\title{
ANALISIS NILAI RELIGIUSITAS DALAM NOVEL TUHAN, MAAF ENGKAU KUMADU KARYA AGUK IRAWAN MN
}

\author{
Irma Sendy Aristya \\ aristyairma90@gmail.com \\ Dosen STKIP Muhammadiyah Pagaralam
}

\begin{abstract}
This study aimed to describe the values of religiosity in the novel Tuhan, Maaf Engkau Kumadu by Aguk Irawan MN. This type of research is qualitative. Metode yang used in this research is the method deslriptif. The results of this study are as follows: First, religious values associated with Qalb or liver (which has the pleasure principle) which is reflected from the main character is that Ridho is a young man who greatly admired her idol Nisa. He always thought of Nisa every second of it, it makes Ridho feel happy. Because kept thinking and shadowing Nisa through dreams regardless of his Lord. Second, Fuad is feeling the most in the so-called conscience, which serves as a store of memory. Fuad demonstrated by Ridho who underwent a drastic change in his life. Now he is getting misguided souls burning would love to Nisa that led to the injury because only love is unrequited. Third, the ego aspect demonstrated by Ridho when he was uniting between feelings of love and compassion through the pieces out as a form hubb (love) to Nisa. Selfishness is done the main character just thinking of the girl regardless of the people around him. And the fourth, aspects of behavior shown by Ridho as the main character is less normal and can not be in the logic of reason.
\end{abstract}

Keywords: value, religiosity, novel

\section{PENDAHULUAN}

Menurut Nurlailah (2006:225) sastra adalah setiap bahasa berbentuk syair berisi imajinasi yang baik, ilustrasi yang indah, makna yang kuat dan hikmah yang sesuai yang berpengaruh terhadap pembinaan jiwa, kepekaan rasa dan kefasihan lisan. Dalam bahasa Indonesia, kata sastra biasa digunakan untuk merujuk kepada semua jenis tulisan yang memiliki arti atau keindahan tertentu. Namun secara garis besar sastra dapat dikelompokkan menjadi dua bagian yakni, sastra tulis dan sastra lisan.

Novel merupakan salah satu bentuk karya sastra yang menyuguhkan tokoh-tokoh dan menampilkan serangkaian peristiwa secara tersususn. Namun, jalan ceritanya dapat menjadi suatu pengalaman hidup yang nyata, dan lebih dalam lagi novel mempunyai tugas mendidik pengalaman batin pembaca atau pengalaman manusia.

Gambaran kehidupan yang terpancar dalam novel akan memberikan pengalaman baru bagi masyarakat atau pembaca, karena apa yang ada dalam masyarakat tidak sama persis dengan apa yang ada dalam karya sastra. Melalui penafsirannya, pembaca akan memperoleh hal-hal yang mungkin tidak diperolehnya dalam kehidupan. 
Dikaitkan dengan pembelajaran di sekolah, Badudu (2003:1-2) menyatakan bahwa pembelajaran sastra bertujuan untuk meningkatkan kemampuan siswa dalam mengapresiasikan sastra, berhubungan juga dengan latihan mempertajam perasaan, penalaran, dan daya khayal, menumbuhkan kepekaan terhadap masyarakat, budaya, dan lingkungan hidup.

Keadaan seperti ini menuntut keberadaan karya sastra yang dapat memenuhi kebutuhan karya yang dapat mempertajam perasaan, penalaran, dan daya khayal, apalagi karya tersebut memiliki latar yang bersumber dari lingkungan siswa sebagai pembaca.

Dalam hal ini nilai-nilai religius sangat mempengaruhi dalam kehidupan seseorang menjalani kehidupannya. Bidang kajian dalam religiusitas tidak terlepas dari aspek religi yang mengatur hubungan manusia dengan Allah, hubungan manusia dengan sesama manusia, dan hubungan manusia dengan lingkungannya. Religiusitas merupakan suatu norma yang mengatur segala sesuatu berdasarkan atau berlandaskan pada agama atau keagamaan yang didasari oleh jiwa (psikis) seseorang tersebut.

Menurut Atmosuwito (2005:123-124), religiusitas atau religius berasal dari kata religion yang berarti "perasaan keagamaan". Perasaan keagamaan adalah segala perasaan dan sikap batin yang ada hubungan dengan Tuhan seperti perasaan dosa (guilt feeling), perasaan takut (fear to god), dan mengakui kebesaran Tuhan (god's glory). Nilai religius dalam sastra adalah nilai-nilai yang mampu menyampaikan ajaran-ajaran agama atau yang berhubungan dengan Tuhan.

Berdasarkan uraian latar belakang di atas, penulis tertarik untuk meneliti novel Islami yang berjudul Tuhan, Maaf Engkau Kumadu bkarya Aguk Irawan Mn. Penelitian ini bertujuan untuk membahas tentang nilainilai religiusitas terutama dari aspek kepribadian pada tokoh utama (Aku). Novel ini menonjolkan empat sistem aspek religiusitas yang dilihat dari struktur kepribadian. Kajian sastra yang mengaitkan bagaimana seorang muslim yang menjalani kehidupannya dengan penuh pertimbangan dan kebimbangan dalam keterikatan terhadap agamanya (religiusitas) untuk menentukan akhir dari perjalanan hidup yang telah dijalani oleh tokoh utama. Peneliti memilih novel Tuhan, Maaf Engkau Kumadu karya Aguk Irawan Mn, dengan alasan bahwa novel ini menggambarkan kehidupan seorang musim, yang dilihat dari segi religiusitas seorang tokoh utamanya. Menurut peneliti, novel tersebut dapat menyingkapi gambaran yang akan dikaji, yakni nilai-nilai religiusitas. Masalah penelitian ini dapat dirumuskan bagaimanakah religiusitas tokoh dalam novel Tuhan, Maaf Engkau Kumadu karya Aguk Irawan Mn. 
Penelitian ini diharapkan dapat bermanfaat bagi penulis, pembaca, dan pengajaran sastra. Bagi penulis, penelitian ini diharapkan dapat membantu memahami tingkat keimanan dari analisis nilai religiusitas tokoh utama dalam karya sastra khususnya novel. Bagi pembaca, hasil penelitian ini dapat berguna dan bermanfaat untuk bahan bacaan sastra Indonesia dalam hal analisis sebuah novel. Bagi pengajaran bahasa dan sastra Indonesia, penelitian ini diharapkan dapat dijadikan sebagai acuan atau patokan dalam mengapresisasikan karya sastra novell. Tujuan penelitian ini adalah untuk mendeskripsikan nilai-nilai religiusitas tokoh utama dalam novel Tuhan, Maaf Engkau Kumadu karya Aguk Irawan Mn.

\section{METODE PENELITIAN}

Metode merupakan cara kerja dalam memahami objek yang menjadi sasaran penelitian. Peneliti dapat memilih salah satu dari berbagai metode yang ada dan sesuai dengan tujuan, objek, sifat ilmu atau teori yang mendukung. Dalam penelitian, objeklah yang menentukan metode yang akan digunakan. Adapun metode penelitian yang pada penelitian kualitatif ini adalah metode deskriptif analisis yang mengungkap keadaan yang sebenarnya dalam novel. Metode ini didasarkan pada data yang akan dianalisis berupa teks karya sastra novel Tuhan, Maaf Engkau Kumadu karya Aguk Irawan Mn.
Metode deskriptif analitik adalah metode yang digunakan dengan cara menganalisis dan menguraikan untuk menggambarkan keadaan objek yang di teliti yang dijadikan pusat perhatian dan penelitian (Ratna, 2004:39). Sumber data dalam penelitian ini adalah novel Tuhan, Maaf Engkau Kumadu karya Aguk Irawan Mn dengan jumlah halaman 391, diterbitkan oleh Glosaria Media, November 2013.

Pendekatan yang digunakan dalam penelitian ini adalah pendekatan psikologis. Menurut Semi (2013:45) pendekatan psikologis adalah pendekatan penelaah sastra yang menekankan pada segi-segi psikologis yang terdapat dalam suatu karya sastra. Psikologi dalam sastra adalah dalam pengkajian riwayat hidup pengarang, yaitu dalam hal menanggapi riwayat hidup pengarang membantu memahami karya mereka. Dengan memahami kejiwaan, sikap hidup, dan cara berpikir sastrawan, akan memudahkan kita menemukan makna yang tersembunyi dibalik tulisan-tulisan mereka (Semi, 2013:47).

Teknik pengumpulan data dalam penelitian menggunakan teknik penelitian dokumentasi. Menurut Sugiyono (2013:329) dokumen merupakan catatan peristiwa yang sudah berlalu. Dokumen bisa berbentuk tulisan, gambar atau karya-karya monumental dari seseorang. Dokumen yang berbentuk tulisan misalnya catatan harian, sejarah kehidupan, ceritera, biografi, 
peraturan, kebijakan. Dokumen yang berbentuk gambar, misalnya foto, gambar hidup, sketsa dan lain-lain. Dokumen yang berbentuk karya seni, yang dapat berupa gambar, patung, film dan lain-lain. Teknik penelitian dokumentasi adalah ditujukan memperoleh data langsung dari novel Tuhan, Maaf Engkau Kumadu karya Aguk Irawan $\mathrm{Mn}$, teknik tersebut digunakan untuk memperoleh data analisis tokoh utama dari segi religiusitas yang menjadi objek kajian.

Teknik analisis data yang digunakan dalam penelitian ini adalah teknik analisis konten. Analisis konten berusaha menganalisis dokumen untuk diketahui isi dan makna yang terkandung dalam dokumen tersebut (Jabrohim, 2012:7). Menurut Endraswara (2011:160) analisis konten merupakan model kajian sastra yang tergolong baru. Kebaruan ini dapat dilihat dari sasaran yang hendak diungkap, yakni analisis konten digunakan apabila sipeneliti ingin mengungkap, memahami, dan menangkap pesan karya sastra. Analisis konten dalam bidang sastra merupakan upaya sastra dari aspek ekstrinsik.

Aspek-aspek yang melingkupi diluar estetika struktur sastra itu dibedah, dihayati, dan dibahas mendalam.

\section{PEMBAHASAN}

Berdasarkan hasil penganalisisan dan pengidentifikasian pada novel Tuhan Maaf Engkau Ku Madu karya Aguk Irawan MN, terdapatlah empat aspek religitusitas yang di bahas sebagai berikut. Selanjutnya, menurut pendapat Sukamto (dikutip Jalaluddin, 2010:214) kepribadian religius terdiri dari empat sistem atau 4 aspek religiusitas dalam novel ini sebagai berikut. Yang pertama, Qalb adalah hati. Qalb menganut prinsip kesenangan (pleasure principle), yang menghendaki agar segala sesuatu segera dipenuhi atau dilaksanakan. Qalb yang tergambar dari tokoh utama adalah bahwa Ridho adalah seorang pemuda yang sangat mengagumi Nisa sang pujaan hatinya. Ia selalu memikirkan Nisa disetiap detiknya, hal itu membuat Ridho merasa senang. Karena terus memikirkan dan membayangi Nisa lewat mimpi dan petanda-petanda lainnya, membuat Ridho mengkheb ndaki agar segera dapat meminang Nisa sebagai calon pendamping hidupnya. Yang kedua, Fuad adalah perasaan yang paling dalam yang biasa disebut hati nurani, yang berfungsi sebagai penyimpan daya ingatan. Fuad ditunjukkuan oleh Ridho yang mengalami perubahan drastis dalam hidupnya. Kini ia semakin tak terarah jiwanya membara akan cintanya kepada Nisa yang berujung pada luka karena cintanya hanya bertepuk sebelah tangan.

Nisa yang selalu menjadi bayangbayang dalam hidup Ridho telah memiliki calon pendamping hidup dan yang pasti bukan pemuda bernama Ridho. Ridho yang mendapatkan surat balasan dari Nisa yang 
menyatakan demikian, tak kuasa menahan kepedihan yang ia rasakan. Dunia seakanakan gelap. Dan ia pun tidur dalam suasana terkikis dan alunan puisi yang lamat-lamat menyerukan nama Nisa. Tak dapat di pungkiri kesedihan yang dirasakan oleh Ridho dalam aspek fuad. Dalam pembahasan tersebut aspek fuad sama dengan teori yang dikatakan oleh teori Sukamto.

Yang ketiga, aspek ego ditunjukkan oleh Ridho saat ia sedang menyatukan antara perasaan cinta dan kasihnya melalui potongan tahu sebagai bentuk hubb (cinta) kepada Nisa. Aspek ego ditunjukkan oleh Ridho saat ia sedang menyatukan antara perasaan cinta dan kasihnya melalui potongan tahu sebagai bentuk hubb (cinta) kepada Nisa. Sebelum ia disandingkan di dunia nyata dan membagi kebahagiaan kepada orang tua serta adik-adiknya, ia harus mempersembahkan makna yang hakiki sebagai perwujudan cinta. Ia sungguh bahagia, sebab ia sudah dipertemukan oleh Allah mengenai cinta murni dari benih-benih cinta yang sudah ia sebarkan di hamparan pasir. Al hubb, cinta murni. Bahkan sari cinta yang ia saring lewat berbagai proses. Hasilnya adalah beberapa potong tahu. Itulah perwujudan makna cinta yang Ridho persembahkan untuk Nisa. Yang keempat, aspek tingkah laku yang ditunjukkan oleh Ridho sebagai tokoh utama dirasa kurang normal dan tidak dapat di nalar logika. Cinta yang begitu besar kepada Nisa telah membutakan mata hatinya.

Sehingga ia pun tidak menghiraukan orang-orang yang berada di sekitarnya termasuk ibunya yang selalu mengkhawatirkannya. Hal tersebut sama dengan pendapat Sukamto yang mengatakan tingkah laku ditentukan oleh keseluruhan pengalaman yang disadari oleh pribadi. Apabila dikaitkan dengan hubungan cerita dalam novel dengan fenomena pada saat ini mungkin dapat terjadi, karena kepribadian manusia didunia ini berbeda-beda. Baik dalam sikap ketaatan dan kepatuhan kepada Tuhan, keagaaman serta kepribadian diri sendiri.

Hal yang terpenting adalah kepercayaan yang berasal dari dalam diri untuk bersikap dan mengekspresikan tingkah laku yang baik dimana pun kita berada. Maka dari itu perlunya adaptasi dan komunikasi yang baik bagi sesama umat manusia dimana pun berada. Kemajuan dan perkembangan zaman sekarang ini rasa kepercayaan, kepatuhan, ketaatan terhadap Tuhan dan keagamaan serta kepribadian diri sendiri hampir dilupakan karena banyaknya hal-hal yang dapat mengganggu pribadi seorang tersebut. Banyak manusia khususnya anak muda zaman sekarang yang melangkah dalam kesalahan, seperti memakai obatobatan terlarang, seks bebas diluar nikah, bahkan kelakuan buruk lainnya dapat dilakukannya tanpa berpegang teguh pada 
nilai ajaran agama. Hal tersebutlah yang mempengaruhi kepribadian buruk seseorang.

Kebanyakan dari masyarakat sekarang ini juga baik di kota maupun di pedesaan sudah menganut gaya hidup konsumtif dan bersifat individualis. Keteladanan seorang muslim yang dicontohkan oleh tokoh utama dalam novel ini diharapkan dapat memberikan suatu arahan dan nasihat dalam ajaran islam yang menyadarkan diri kita untuk menjaga hubungan yang baik dalam bermasyarakat, saling kasih mengasihi, saling tolong menolong antar sesama umat manusia, saling menghargai orang lain dan saling menjaga hubungan yang harmonis antara manusia yang satu dengan yang lainnya.

\section{SIMPULAN DAN SARAN}

Berdasarkan hasil analisis dan pembahasan terhadap empat aspek religiusitas yang terdapat dalam novel Tuhan Maaf Engkau Kumadu karya Aguk Irawan MN adalah sebagai berikut. Dalam perkembangannya dimasyarakat Aguk Irawan MN memberikan gambaran serta pelukisan dalam ilmu tentang sifat dan perilaku dalam novel karangannya sangat jelas sekali terlihat pada tokoh-tokohnya. Penggambaran akan religiusitas yang dilakukan oleh tokoh utama juga sangat berpengaruh terhadap kehidupannya seharihari. Hal tersebut tergambar dalam novel karya Aguk Irawan MN, yang merupakan pengarang novel yang memberikan ajaranajaran yang serat dan kental dengan unsur islami dan nilai keagamaan. Melalui ke empat aspeknya tokoh utama juga tergambar dalam novel ini. Keempat aspek tersebut berupa aspek Qalb, Fuad, Ego, dan Tingkah laku. Semua aspek tersebut tergambar dalam kedua novel ini dimana aspek-aspek tersebut sering ditonjolkan oleh tokoh utamanyaa.

Pada novel karya Aguk di penghujung kisahnya tokoh utamanya mengalami perubahan drastis. Perubahan drastis tersebut didasari oleh kejiwaan yang abnormal atau sakit jiwa. Karena pengaruhnya terhadap nilai keagamaan yang salah. Sehingga tokoh utama mengalami penderitaan selama hidupnya.

Di dalam suatu kerya tulis ilmiah implikasi sangat di perlukan untuk membandingkan antara hasil penelitian yang lalu dengan hasil penelitian yang baru di lakukan. Kelebihan novel Tuhan, Maaf Engkau Kumadu yang ditulis oleh Aguk IrawanMn adalah merupakan novel best seller yang ditulis berdasarkan kisah nyata.

Penulis yang lahir di Lamongan 1 April 1979 ini telah banyak menerbitkan tulisan baik fiksi maupun non fiksi. Novel ini adalah salah satu karya penulis disela-sela aktivitasnya sebagai pemimpin redaksi Majalah Kalimah, dan juga sebagai Pengurus Pusat Lembaga Kemaslahatan Keluarga Nahdlatul Ulama (PP-LKKNU) Jakarta, 
bidang riset dan pengembangan. Novel ini dikemas dengan bahasa dan klimaks yang lebih ringan namun tetap mewakili perasaan hingga menitikan air mata ketika membacanya. Banyak kutipan- kutipan puisi klasik Jalaludin Rummi, Fakhrudin 'iraqi, William Sakesphare, WS Rendra, dan dari kisah-kisahnya yang juga diilhami dari novel sang alchemist karya Paulo celho. Banyak pesan-pesan moral yang tersirat tentang bagaimana seorang pencinta itu seharusnya mencintai.

Berdasarkan kesimpulan diatas, maka penulis memberikan saran sebagai

berikut. Pertama, pengarang diharapkan dapat menceritakan hal yang lebih beragam lagi pada novel-novelnya yang akan datang, tentang sufi, religiusitas dan psikologis. Kedua, pendidik diharapkan banyak membaca tentang teori kepribadian dan religiusitas sehingga dapat memberikan pembelajaran tersebut kepada anak didik, dan di dalam perpustakaan agar lebih banyak menambahkan koleksi buku atau novel Islami, untuk bahan kajian tentang ambivalensi sufisme, religiusitas dan psikologi. Sehingga pendidik dan anak didik dapat membaca serta memahaminya. Ketiga, bagi peneliti lain, diharapkan agar penelitian ini dapat dijadikan salah satu wawasan dalam memahami salah satu karya sastra, dan dapat dijadikan sebagai motivasi dan referensi dalam penelitian karya sastra khususnya dalam bentuk karya sastra novel. Dan setelah peneliti melakukan penelitian ini muncul penelitian penelitian baru dengan metode dan teknik yang baru sehingga dapat menumbuhkan motivasi dalam penelitian kesusastraan seperti kajian postkolonialisme, feminisme, kriminalisme, erotisme dan lain sebagainya.

\section{DAFTAR PUSTAKA}

Aminuddin. 2013. Pengantar Apresiasi Karya Sastra. Bandung: Sinar Baru Algasindo.

Atmosuito, Subijantoro. 2005. Perihal Sastra dan Religiusitas dalam Sastra. Bandung: Sinar Baru.

Endraswara, Suwardi. 2011. Metodologi Penelitian Sastra. Yogyakarta: CAPS. Depdiknas. 2011. Kamus Besar Bahasa Indonesia. Jakarta: Gramedia Pustaka Utama. Irawan, Aguk. 2013. Tuhan, Maaf Engkau Kumadu. Yogyakarta: Glosaria Media.

Jabrohim. 2012.Teori Penelitian Sastra. Yogyakarta: Pustaka Pelajar.

Jalaluddin. 2010. Psikologi Agama. Jakarta: PT Raja Grafindo Persada.

Nurgiyantoro, Burhan. 2010. Teori Pengkajian Fiksi. Yogyakarta: Gadja Mada University Press.

Sugiyono. 2013. Memahami Penelitian Kualitatif. Bandung: CV Alfabeta.

Sumardjo, Jakob dan Saini K.M. 2003. Apresiasi Kesusastraan. Jakarta: Gramedia 